\title{
Influence of Finance in Mainstreaming Support for Orphans and Vulnerable Children (OVC) in Nyeri Central District, Kenya
}

\author{
Grace Githae Ngethe ${ }^{1}$, Paul A. Odundo ${ }^{2}$, John K. Mwangi ${ }^{3}$ \\ School of Education, College of Education and External Studies, University of Nairobi, Nairobi, Kenya
}

Email address:

ngethagrace@gmail.com (G. Githae), Odundopaul@yahoo.com (P. A. Odundo), jmkamau@uonbi.ac.ke (J. K. Mwangi)

To cite this article:

Grace Githae Ngethe, Paul A. Odundo, John K. Mwangi. Influence of Finance in Mainstreaming Support for Orphans and Vulnerable Children (OVC) in Nyeri Central District, Kenya. International Journal of Elementary Education. Vol. 4, No. 1, 2015, pp. 8-15. doi: 10.11648/j.ijeedu.20150401.12

\begin{abstract}
Orphaned and Vulnerable Children (OVC) below 8 years represent an extremely vulnerable population due to growing levels of poverty, HIV/AIDS and socio-economic situation in which they live. This makes Public Nursery Schools (PNS) receive greater attention as places to remedy to decline of family and community based support. Schools provide channels for distribution of essential services such as food, healthcare, clothing, education and psychosocial support. Though the goal of expanding Early Childhood Education (ECE) opportunity for all children is integrated global initiatives such as Education for All (EFA) and Millennium Development Goals (MDG), PNS face the burden of fewer resources as the support systems for OVC such as school feeding, health and nutritional care and psychosocial support are linked to Education Finance. Steady provision of funding level ensures that PNS improve wellbeing and learning outcomes of children through whole school interventions. By contrast, deprivation of interventions during the early years results in lifelong deficiencies and disadvantages. The study sought to find out the influence of finance on mainstreaming support for OVC in PNS in Nyeri Central district .The study employed a descriptive survey design with a sample of 19 public nursery schools. Data was collected through questionnaires for head teachers, a nursery school teacher for each school and an interview was conducted with the District Centre for Early Childhood Education (DICECE) programme officer. The study found out that mainstreaming support for OVC was compromised as source of funds were inadequate for OVC support, capacity building for teachers and retention of OVC in schools through, feeding programme, subsidized fees and bursary funds. To avert this crisis, the study recommends that support for OVC should be intensified through increased budgetary allocation and setting up funds earmarked for OVC in PNS.
\end{abstract}

Keywords: Financing Early Childhood Education, Orphans and Vulnerable Children, Public Nursery Schools

\section{Introduction}

The support of vulnerable children in ECE is one of the greatest challenges faced in educational transformation as percentage of the influence of the finance on services is higher compared to other factors such as how culture treats OVC(Abebe,2009)Despite significant increase in basic education enrolment, access to quality education remains low in many countries. Statistics collected by UNICEF in 2008revealed that pre-primary enrolment and completion ratios averaged $79 \%$ in developed countries and $36 \%$ in developing countries and as low as $14 \%$ in Sub-Saharan Africa (UNICEF,2008) This implies that children from wealthiest households and those receiving adequate funding are more likely to attend school than those from poor households. According to a report given by the Ministry of Gender Children and Social Development (MGCSD) in 2007, access to ECE for OVC aged 3-5 years remains a challenge as only $28.2 \%$ are able to attend school. The rest $(71.8 \%)$ miss or drop out of school due to deprivation, poverty, lack of care, school fees, learning materials and psychosocial support(GOK,2007)

In the Dakar Framework for Action 2001, developing countries pledged to enhance investments in basic education while rich nations promised to increase aid to ensure that no country committed to Education for all will be thwarted in achievement for EFA by lack of resources (UNESCO,2010).However finance remains a major barrier to 
education as the financing gap is larger than previously assumed. Kenya is improving the protective and legal environment for the growing number of OVC in ECE but support for OVC in education policies has been addressed through removal of school fees primary education tier. However this has not been the case for PNS as the largest share of financing comes from parents and fees charged almost entirely covers payroll cost for teachers (UNESCO, 2005) The governments contribution to ECE is less than $0.1 \%$ compared to $61 \%$ in primary schools (Belfield, 2006). This reflects low political commitment to ECE making coverage extremely variable and largely dependent on family income or community involvement. Other funding aimed at OVC support is the Cash Transfer Fund (CTF) Programme where extremely poor households are provided periodically with cash subsidies (GOK, 2007). However education for children below 6 years is not a priority in the disbursement of funds. In Nyeri Central district the number of households with OVC had reached4,261 by 2013 yet only 358 had benefitted from the CTF. Although the Ministry Of Education (MOE) strategic plan 2006-2011 proposed planned increase in enrollment of OVC in ECE by the year 2011 the role of PNS in the provision of care and support for OVC has not featured prominently as adequacy of finance is an aspect in the planning and implementation of OVC interventions. For PNS to be transformed into caring schools that emphasize care for OVC coupled with quality education, there is need for adequate financing to meet needs of all children in ECE centers.

\section{Statement of the Problem}

Orphan hood and vulnerability are identified as impediments in accessing education and retention in nursery schools for children. In support of this contention UNESCO (2008);Subbarao\&Coury (2004) confirmed that OVC are likely to have limited access and retention in schools due malnutrition, poor health, inadequate uniform and learning materials, incompetent staff, lack of school fees and low attention due to hunger. Financing of ECE has potential to redress challenges and inequalities through adequate funding but can also reinforce if funding is inadequate to the competing needs of the children in schools. In Kenya, households are a source of domestic funding not only for tuition fees but also payments for textbook, materials, uniforms and other inputs needed for children to attend PNS(Belfield,2006) Requirements to pay for such inputs may prelude OVC from attending school as households taking care of OVC opt to enroll them in PNS as the cost for private preschools is higher.

The society has over the years entrusted the Government of Kenya to support schooling at all tiers and adequately support children disadvantaged through orphan hood and sustained vulnerability which they are exposed to at home. Provision of special attention to mitigate barriers that impede OVC access to equal benefit with all other children involves interventions such as overcoming hunger and malnutrition through financing school feeding programmes (UNESCO, 2008) in addition to reduction of direct and indirect costs of education which limits participation of OVC in education.

Though these interventions are supported in educational and national policies they cannot be reached if there is insufficient funding and having no plan for reaching sufficient funding in future as a adequate education is an investment in a state's future. To increase retention of OVC in schools while addressing other factors such as availability and adequacy of finance which most times is inadequate remains an issue in many PNS. It is in this view that the study sought to establish how adequacy finance has influenced mainstreaming support for OVC in PNS in Nyeri Central district

\section{Research Methodology}

The study applied a survey design to source for primary data from PNS head teachers, teachers and Education officer. Secondary data was sourced from wide range of literature review which comprised of documentary sources on similar studies and policy documents on ECE.

The study covered a population of total of 40 PNS in Nyeri central district. Krejcie and Morgan(1970) equation was used to get a sample of 36 schools. However the sample size was big for the study and Cochrans 1997 correction formula for large samples was used to narrow the sample size to19 schools. The respondents were sampled using simple random procedures while purposive Education officer was sampled. The instruments for collecting data were questionnaires for head teachers and teachers. An indicate question for who and for what interview was conducted with the DICECE programme officer.

\section{Findings and Discussions}

The study sought to establish the situation of OVC in nursery schools by finding out the number enrolled, attendance and access to basic needs. On OVC enrolment, teachers were asked to indicate the number of OVC enrolled in the nursery schools. The study found out that out of 15 schools 10 (67\%) had enrolled a few (1-5) OVC, compared to $2(13 \%)$ that had $6-10$ and $3(20 \%)$ with $11-15$, This implies that substantial number of schools $10(67 \%)$ had enrolled a small number of OVC due inadequate funding. The schools were better placed to provide support services for OVC as the number enrolled was low. However the $3(20 \%)$ schools with high OVC enrolment needed more funding to cater for the demands the children including OVC.

Table 1. Finance and OVC Enrolment in Nursery Schools.

\begin{tabular}{lllllll}
\hline \multirow{2}{*}{ No of OVC Enrolment } & \multicolumn{2}{l}{$\begin{array}{l}\text { Northern } \\
\text { Zone }\end{array}$} & \multicolumn{2}{l}{$\begin{array}{l}\text { Southern } \\
\text { Zone }\end{array}$} & \multicolumn{3}{l}{ Total } \\
\cline { 2 - 8 } & $\boldsymbol{N}$ & $\mathbf{\%}$ & $\mathbf{N}$ & $\mathbf{\%}$ & $\mathbf{N}$ & $\mathbf{\%}$ \\
\hline $1-5$ & 5 & 72 & 5 & 62.5 & 10 & 67 \\
$6-10$ & 1 & 14 & 1 & 12.5 & 2 & 13 \\
$11-15$ & 1 & 14 & 2 & 25.0 & 3 & 20 \\
Total & 7 & 100 & 8 & 100 & 15 & 100 \\
\hline
\end{tabular}


Further findings indicated that out of 7 respondents in the Northern Zone 5(72\%) had enrolled 1-5 OVC and 1(14\%) had 6-10 and the other 1(14\%) had11-15. In the Southern zone out of 8 schools that responded $5(62.5 \%)$ had enrolled 1-5 OVC, $12.5 \%$ had $6-10$ while $2(25 \%)$ had enrolled $11-$ 15.Though there is compelling evidence from literature that traditionally in Kenya, OVC are absorbed into the extended family systems (USAID, 2010) it seems that traditional social safety net is under severe threat due to financial strain leading to incapability of the families to cater for the needs of OVC. This is evidenced in the study by the high number of OVC enrolled5(33\%) schools enrolling 6-15 OVC which rationalizes the need to provide funds to facilitate support for OVC to access education.

\section{Finance and OVC Access to Basic Needs}

Respondents were asked whether OVCs have access to basic needs such as daily meal, clothing, and learning materials. UNICEF (2004) notes that without collective financial action at the school level, the burden of OVC is likely to diminish developmental prospects, reduce school enrolment and increase social inequity and instability. The responses elicited are shown in Table 2

Table 2. OVC Access to Basic Needs.

\begin{tabular}{|c|c|c|c|c|c|c|}
\hline \multirow{2}{*}{ Response } & \multicolumn{2}{|c|}{ Northern zone } & \multicolumn{2}{|c|}{ Southern zone } & \multicolumn{2}{|l|}{ Total } \\
\hline & $N$ & $\%$ & $\mathbf{N}$ & $\%$ & Frequency & $\%$ \\
\hline Yes & - & 0 & 3 & 38 & 3 & 20 \\
\hline No & 7 & 100 & 5 & 62 & 12 & 80 \\
\hline Total & 7 & 100 & 8 & 100 & 15 & 100 \\
\hline
\end{tabular}

As evidenced in Table 2, out of 15 respondents 12 (80\%) of the OVC enrolled in both strata of nursery schools did not have or had limited access to basic needs while only $3(20 \%)$ had access. This implies that different financing mechanisms are expected to cater for the $80 \%$ who did not have access to basic needs. Meanwhile 3(38\%) of the 8 respondents in the Southern zone indicated that OVC accessed basic needs but the number is small compared to $12(80 \%)$ of who did not have access in both zones. Majority of OVC did not have access to basic needs which necessitated schools to have interventions to support OVC such as fund raising. This situation may push rising numbers of OVC into the streets lowering participation. Schools should therefore act as safety nets for OVC by spending more time soliciting support systems such as feeding programmes, psychosocial support and provision of learning materials and clothing to enhance retention at ECE tier.

\section{Source of Funding in Nursery Schools}

Sources of funding and mechanisms through which revenues are raised have implication on adequacy, sustainability and equity in education finance. The study sought to establish sources of funding for the sampled nursery schools based on mainstreaming support for OVC. There was unanimous response $16(100 \%)$ that the main source of funds for the ECE centres was from levies paid by parents. When interviewed on the sources of funding the District Center for Early Childhood Education (DICECE) officer stated that ECE Department at the district level receives funds from the government, parents and community support programmes but funding from the government did not cater for the education of children in ECE centres but for coordinating DICECE programmes and in-service training for teachers. The decision to support OVC was left in the hands of head teachers in the schools.

\section{Specific Funding for OVC in Nursery Schools}

In order to retain disadvantaged children in school and realize equality, schools need additional resources especially for children with special needs such as physically disabled, orphans and HIV/AIDS infected and affected. Teachers were asked to state whether there were specific funding systems for OVC in their schools. All the head teachers 16 (100\%) reported that schools had no specific funding systems earmarked for OVC. Though aware of the plight of OVC, establishing earmarked vote head for OVC though necessary seemed to be a challenge in the $16(100 \%)$ schools which jeopardized the head teacher's ability to mainstream maximum support for OVC. Vegas et al (2011) recommends that students with special needs present a greater diversity of needs including physical, cognitive and behavioural which requires additional spending to address. The allocation of specific grants for schools enables institutions to provide school based care and to meet the material needs of learners where appropriate(Allemano et al,2009). On the same vein the indicated that there were no specific funding systems for $\mathrm{OVC}$ at the Ministry of Education (MOE) office although some benefited from the community support grants and sometimes from Non Governmental Organization (NGO) for children living in Charitable Children's Homes. The only children getting some financial support were those living in Charitable Children Homes yet this was quite a small number compared to those OVC living with extended families. This situation exposed OVC outside children's homes to extreme vulnerability due to lack of funds.

\section{Accessibility of Funds and Support for OVC}

From the identified sources of funding the study sought to find out how accessible was funding to the nursery schools management and for school operations. Table 3.shows the frequencies of access to funding for OVC and institutional support or management. 
Table 3. Accessibility of Funds and OVC Support.

\begin{tabular}{lllllll}
\hline \multirow{2}{*}{ Accessibility of funds } & \multicolumn{3}{c}{ Northern zone } & \multicolumn{2}{c}{ Southern zone } & \multicolumn{2}{c}{ Total } \\
\cline { 2 - 7 } & $\boldsymbol{N}$ & $\boldsymbol{\%}$ & $\mathbf{N}$ & $\mathbf{\%}$ & $\mathbf{N}$ & $\mathbf{\%}$ \\
\hline Monthly & 3 & 37.5 & 3 & 37.5 & 6 & 37.5 \\
Once per term & 4 & 50.0 & 4 & 50.0 & 8 & 50.0 \\
Once per year & 1 & 12.5 & 1 & 12.5 & 2 & 12.5 \\
Total & 8 & 100 & 8 & 100 & 16 & 100 \\
\hline
\end{tabular}

The findings from the study depict that out of the total number of 16 respondents $6(37.5 \%)$ of the nursery schools accessed funds from parents on monthly basis, 8(50\%) accessed funds once per term and $2(12.5 \%)$ accessed yearly (Table 3) This showed that the 6(37.5\%) of the schools had unsteady supply of funding contrary to head teachers expectation that school fees should be paid at the beginning of the term failure to which school operations would be adversely affected including supporting OVCs.

Further analysis indicated that the situation was similar in both zones with $3(37.5 \%)$ accessing funds monthly, 4(50\%) accessing once per term and $1(12.5 \%)$ accessing yearly. Such unsteady flow of funding culminated into inability of the head teachers to effectively mainstream support for OVC in school as unsteady flow of finance hindered sustainability of any support structures especially for OVC.

\section{Reliability of Funds in Supporting School Operations}

The study sought to establish how reliable the funds were in supporting school operations and support for OVC. The responses in Table 4 showed adequacy or inadequacy of financial flow to support OVCs and school management.

Table 4. Reliability of Funds in Supporting Operations.

\begin{tabular}{lllllll}
\hline \multirow{2}{*}{ Reliability of funds } & \multicolumn{3}{c}{ Northern zone } & \multicolumn{2}{c}{ Southern zone } & \multicolumn{2}{c}{ Total } \\
\cline { 2 - 7 } & $\mathbf{N}$ & $\boldsymbol{\%}$ & $\mathbf{N}$ & $\mathbf{\%}$ & $\mathbf{N}$ & $\mathbf{\%}$ \\
\hline Very Adequate & - & - & - & - & - & - \\
Adequate & - & - & 2 & 25.0 & 2 & 12.5 \\
Somewhat Adequate & 3 & 37.5 & 3 & 37.5 & 6 & 37.5 \\
Inadequate & 2 & 25.0 & 3 & 37.5 & 5 & 31.0 \\
Extremely Inadequate & 3 & 37.5 & - & - & 3 & 19.0 \\
Total & 8 & 100 & 8 & 100 & 16 & 100 \\
\hline
\end{tabular}

The results in Table 4 indicate that funds were adequate for school operations in $2(12.5 \%)$ out of 16 schools that responded, $6(37.5 \%)$ indicated that funds were somewhat adequate,5(31\%) said that funds were unreliable and 3(19\%) said that the funds were extremely inadequate not only in the running of school programmes but also for OVC support. Further analysis indicated that in the $3(37.5 \%)$ schools out of the 8 in the Northern zone, funds were very unreliable in supporting school operations. This implies that a total of $5(62.5 \%)$ of the 8 schools in this zone faced challenges in establishing support systems of OVC as the funds received were not adequate as OVC support systems required reliable and sustained funding. The situation was similar in the Southern zone as only $2(25 \%)$ out of the 8 schools indicated that the funds were adequate compared to $5(37.5 \%)$ who indicated extreme inadequacy of funds. The results of these findings concur with the findings by WERK (2004) that OVC faced challenges in primary schools due to inadequacy of funds from the funding sources.

\section{Finance and Continuity for OVC}

The longer a child spends in school over the course of the year, the greater their opportunity to master the curriculum as student absenteeism reduces learning time. For this to be OVC retention in schools is to abolish school fees or provide bursaries for children in vulnerable circumstances (Bolerand Caroll, 2003) Based on this understanding the study sought to establish the effect of the adequacy of funds on establishing support systems for OVC in the sampled schools. This was achieved by finding out if head teachers sent children home to collect school fees. Table 5shows regularity of sending children home to collect fees from parents who are already financially strained.

Table 5. Frequency of Sending Children for School Fees.

\begin{tabular}{|c|c|c|c|c|c|c|}
\hline \multirow{2}{*}{ Responses } & \multicolumn{2}{|c|}{ Northern zone } & \multicolumn{2}{|c|}{ Southern zone } & \multicolumn{2}{|c|}{ Total } \\
\hline & $N$ & $\%$ & $\mathbf{N}$ & $\%$ & $\mathbf{N}$ & $\%$ \\
\hline Every month & 3 & 37.5 & 5 & 62.5 & 8 & 50.0 \\
\hline Once per term & 3 & 37.5 & 3 & 37.5 & 6 & 37.5 \\
\hline Never & 2 & 20.0 & - & - & 2 & 12.5 \\
\hline Total & 8 & 100 & 8 & 100 & 16 & 100 \\
\hline
\end{tabular}

The findings in Table 5 shows that cumulatively $8(50 \%)$ out of the 16 head teachers sent the children home to collect school fees every month, $6(37.5 \%)$ sent them once per term and $2(12.5 \%)$ never sent the children home. This implies that majority of the schools $14(87.5 \%)$ had very low capacity to support OVC as there was no steady flow of finance to sustain support systems. In the same context the study found out that out of the 8 schools in Northern zone 3(37.5\%) sent children home for school fees every month, 3(37.5\%) once per term with a few $2(20 \%)$ who never sent children home. Schools in the Southern zone faced more challenges on adequacy with all $8(100 \%)$ of the schools sending children home to collect school fees. From the findings the ECE sector is not adequately funded as schools require families to cover some costs as $14(87.5 \%)$ out of the 16 schools did not have steady flow of finances for supporting school operations. The head teachers had to keep reminding the parents to pay by sending children home. On the same vein teachers were asked to state whether OVC were among those sent home for school levies. Responses indicated that there was significant number of schools $11(68 \%)$ out of the 16 in both Southern and Northern zones that sent OVC home for school fees implying that the schools did not have enough funds for mainstreaming support for OVC by not sending them home for school fees. This placed a burden to families with OVC findings concur with Belfield (2006) who said that while school fees may be needed as a source of revenue for the schools in the low income families it represents a burden to the parents with low income, the poor and disadvantaged. Though this is the case the findings also show that there is 
quite a substantial number of schools $5(32 \%)$ out of 16 that had managed to retain OVC in schools. This is in line with recommendations by Bolerand Caroll (2003) that schools should abolish school fees or create inclusive policies and practices in order to avoid drop out of OVC due to unaffordable school fees.

\section{School Funding and Adequacy for OVC}

Adequacy is a fair method for funding schools as it guarantees all students an opportunity for success by meeting their needs no matter where they live or life circumstances (Peter,2003). It goes beyond equity by recognizing that some children face challenges such as poverty and disability that require extra support to meet educational goals. On whether the funds obtained were equivalent in meeting the needs of the ECE $12(75 \%)$ out of $16(100 \%)$ respondents said that the funding obtained did not meet all the needs of the centres. The respondents said that the demands of some vote heads such as paying of wages for the staff and purchase of teaching and learning materials were not met as the level of default was higher compared to irregular payments of school levies by the parents.

\section{Funds Received, Expected Expenditure and Support for OVC}

The study sought to find out whether funds received annually were equivalent to the expected expenditure per child within the ECE centres. Respondents were required to state the amount of fees received from every child annually. Table 6 shows the amount of funding received and expected expenditure for each child.

Table 6. Funds Received and Expected Expenditure.

\begin{tabular}{llll}
\hline Category & Average of Funds received per child( inKsh) & Average Expected Expenditure per child (in Ksh) & Deficit \\
\hline Southern zone & 1542 & 3350 & 1808 \\
Northern zone & 1080 & 3500 & 2420 \\
Average & 1311 & 3425 & 2114 \\
\hline
\end{tabular}

On average, schools in the Northern zone received 1080 Ksh annually from each child which was less compared to schools in the Southern zone which received Ksh1,542. On average schools received Ksh 1,311 per child with the expenditure being more than thrice the consumption value; Ksh3,425 (Table 6 ). This implies that the economic cost per child was too high compared to the available funds hence the head teachers faced challenges in scaling up interventions for $\mathrm{OVC}$ as adequate funding was required to be provided for each student in order to guarantee the opportunity for an appropriate education for all. The findings further indicate that in both Southern and Northern zone there was a deficit in terms of the amount received and the expected expenditure per child with the Northern zone having a larger deficit of Ksh 2,420 compared to the Southern zone with Ksh 1,808 annually. This implies that though the head teachers were willing to financially support OVC, it was highly hindered by low financing. The unexpected fluctuations in per pupil funding hampered the ability of schools to provide a constant educational experience for all children each year. Country et al. (2004) says that any decision by the head teachers to scale up interventions is influenced by the cost of scaling up and the financial capacity of the implementers and institution capability.

Record keeping for OVC in schools is essential for the formulation of effective policy, planning and budgeting for their education. In the absence of such data the policy makers would not understand the magnitude of children's needs and financial resources needed to address them. All the respondents $15(100 \%)$ indicated that they did not have specific documents of OVC and their participation in school. The respondents said that it would have been too expensive to buy files for each individual child. This is supported by
Smart (2003) sentiments that though the education sectors have good data systems where information is gathered and analyzed annually on pupil enrolment, pupil drop-out, teacher/pupil ratios, teacher attrition, facilities at schools, and provision of infrastructure However OVC are hardly captured in regular assessments This is attributed to lack of funding specifically by the government for OVC resulting in negligence.

\section{Allocation of Funds and Feeding Programme}

School feeding is one of the interventions that support nutrition for OVC in children as it gives the child a healthy head start and paves the way for a promising future (Subbarao and Coury, 2004). Therefore school feeding programme requires more allocation for sustainability and balanced nutrition. Based on this, respondents were asked to state the percentage of funds received that was allocated to feeding programme. The findings are shown in Table 7

Table 7. Funds Allocation to Feeding Programme.

\begin{tabular}{lllllll}
\hline \multirow{2}{*}{ Allocation (\%) } & \multicolumn{2}{l}{ Northern zone } & \multicolumn{2}{c}{ Southern zone } & \multicolumn{2}{c}{ Total } \\
\cline { 2 - 7 } & $\boldsymbol{N}$ & $\boldsymbol{\%}$ & $\mathbf{N}$ & $\mathbf{\%}$ & $\mathbf{N}$ & $\%$ \\
\hline None & 2 & 25 & 2 & 25 & 4 & 25 \\
$1-19$ & 4 & 50 & 2 & 25 & 6 & 37.5 \\
$20-39$ & 2 & 25 & 4 & 50 & 6 & 37.5 \\
$40-59$ & - & - & - & - & - & - \\
Total & 8 & 100 & 8 & 100 & 16 & 100 \\
\hline
\end{tabular}

As presented in Table 7, 4(25\%) out of the 16 schools did 
not have a school feeding programme as no funds were allocated 6(37.5\%) allocated $1-19 \%$ and 6(37.5\%)allocated $20-39 \%$ to the feeding programme. Due to inadequacy of funds $4(25 \%)$ of the head teachers had done very little to support OVC in terms of provision of a daily meal. The data further shows that though majority $4(50 \%)$ of the schools in the Northern zone had managed to have a feeding programme yet the allocation was too little (1-19\%) to fully cater for good and balanced meals for OVC. Southern zone schools allocated more with 4(50\%) allocating 20-39\%.From these findings indicated little was allocated to feeding programmes both in Northern and Southern zone schools. The implication of little funding and less allocation affected any efforts aimed at assisting OVC through viable school feeding programmes.

\section{Finance and Remuneration for Teachers}

The study sought to find out the remuneration as well as other aspects of staff development in the schools and relationship to OVC support. Table 8 shows the range of teachers' salaries.

Table 8. Monthly Income of the Teacher.

\begin{tabular}{lllllll}
\hline \multirow{2}{*}{ Salary in Ksh } & \multicolumn{2}{l}{ Northern zone } & \multicolumn{2}{l}{ Southern zone } & \multicolumn{2}{l}{ Total } \\
\cline { 2 - 7 } & $\boldsymbol{N}$ & $\%$ & N & $\%$ & N & $\%$ \\
\hline Below 3,000 & 1 & 14 & - & - & 1 & 7 \\
$3,000-5,000$ & 6 & 86 & 8 & 100 & 14 & 93 \\
Above 5,000 & - & - & & - & - & - \\
Total & 7 & 100 & 8 & 100 & 15 & 100 \\
\hline
\end{tabular}

On teachers salary, cumulatively majority $14(93 \%)$ of the 15 respondent teachers between Ksh 3000-5,000 per month while $1(7 \%)$ earned less thanKsh3,000 indicating that the teachers earnings were relatively poor in both categories. Similarly all teachers $8(100 \%)$ from the Southern zone earned less than Ksh 5,000 whereas in the Northern zone majority $6(86 \%)$ earned betweenKsh3,000-5000 with $1(14 \%)$ earning less than Ksh 3,000 (Table 6). The findings depict that teachers $14(93 \%)$ were not in a capacity to offer financial assistance to OVC due to poor pay. The findings concur with UNESCO (2005) that preschool teachers in Kenya earn a monthly salary that is generally less than half of that of primary school teachers. This low and irregular pay makes the profession unattractive. On the same note, a poorly paid teacher may not be in a capacity to offer any financial support to OVC as low pay leads to low teacher morale in curriculum implementation. All the respondents $15(100 \%)$ indicated that the salary was not commensurate with the services rendered and qualification as some held diploma and degree certificates.. The DICECE officer stated that teachers lacked support from the head teachers as they sometimes stayed for months without pay disadvantaging them from supporting OVCs or any other venture.

\section{Finance and Relevance of Teacher Qualifications to OVC Support}

Teachers were asked to indicate whether qualifications were relevant in handling preschool children and giving support to OVC. Table 9 shows the findings.

Table 9. Sponsorship of Teachers for Refresher Courses.

\begin{tabular}{|c|c|c|c|c|c|c|}
\hline \multirow{2}{*}{ Response } & \multicolumn{2}{|c|}{ Northern zone } & \multicolumn{2}{|c|}{ Southern zone } & \multicolumn{2}{|l|}{ Total } \\
\hline & $\mathbf{N}$ & $\%$ & $\mathbf{N}$ & $\%$ & Frequency & $\%$ \\
\hline Yes & 2 & 29 & - & - & 2 & 13 \\
\hline No & 5 & 71 & 8 & 100 & 13 & 87 \\
\hline Total & 7 & 100 & 8 & 100 & 15 & 100 \\
\hline
\end{tabular}

Cumulatively $5(33 \%)$ out of the 15 teachers felt that professional skills were relevant in supporting OVC, $9(60 \%)$ felt that their professional skills were fairly relevant while 1(7\%) felt their skills were irrelevant to supporting OVC. From the findings showed that there was a substantial number of teachers $10(67 \%)$ in both zones who needed financing for capacity building through refresher courses to enhance skills for curriculum implementation and supporting OVC . The study also found out that in both zones a few $2(13 \%)$ of the $15(100 \%)$ had been sponsored for refresher courses while majority $13(87 \%)$ of the teachers had not secured sponsorship to professional refresher courses from the management of respective schools (Table 9) Inadequacy of funds had jeopardized capacity building for majority of the teachers in order to enhance their skills in class integration of OVC.A closer look at the findings indicate that Southern zone was more affected with all $8(100 \%)$ responding on the negative. Similarly very little had been done to equip teachers with relevant skills to support OVC in the Northern zone as only $2(29 \%)$ of the $7(100 \%)$ teachers had been sponsored for refresher courses. Conclusively, the findings depict that inadequacy of funds for capacity building caused teachers to be ill equipped for support of OVC. Mizell (2010) recommends that policy makers have a responsibility to provide extra financial support to ensure that teachers within the schools engage in continuous professional learning and apply that learning to increase student achievement.

\section{Coping Mechanisms and School Capacity to Support OVC}

Head teachers were further asked to identify the types of financing mechanisms put in place to improve the capacity the schools to help in participation of OVC. Figure 1 shows the measures taken by the head teachers. 


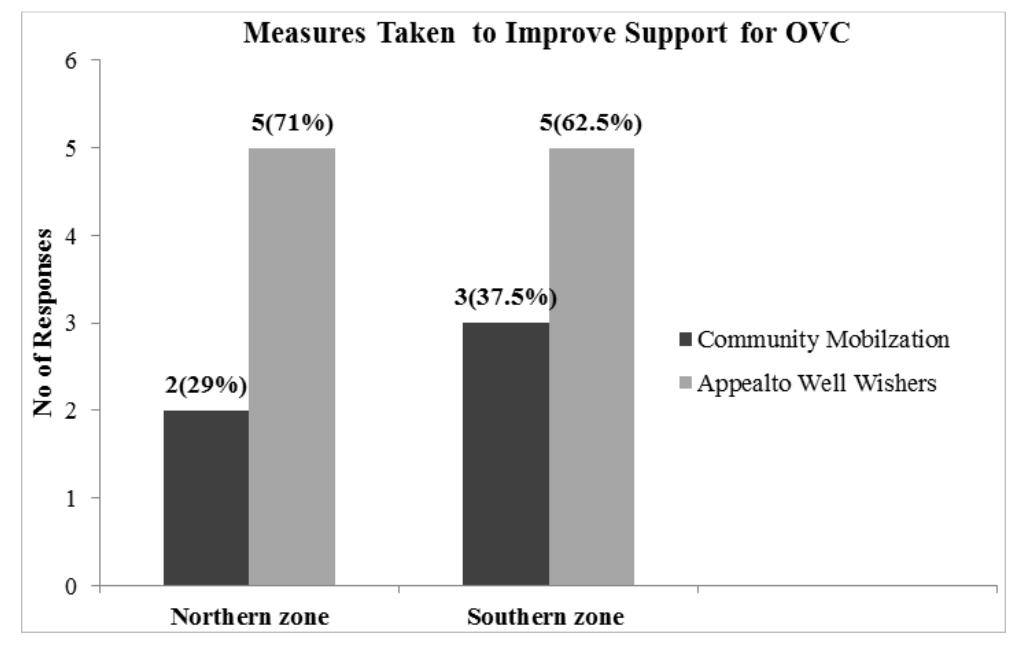

Figure 1. Measures taken to improve support for OVC.

Due to inadequacy of funding from parents, $5(71 \%)$ out of 7 schools in the Northern zone appealed for funds to support OVC from well wishers while $2(29 \%)$ mobilized the community (Figure 1) In the Southern zone 5(62\%) out of 8 respondents indicated that they appealed to well wishers while $3(37.5 \%)$ mobilized the community for funds. From the findings in it can be10(67\%) out of the 15 schools in both zones adopted appealing to well wishers as the main approach to mainstream support for OVC while 5(33\%) mobilized immediate community around the schools for funding. This implies that due to inadequacy of funds sourced from the parents the head teachers provided limited support OVC. However appealing to well wishers was not sustainable as the funds were unreliable because some of the well wishers failed to keep their promise of financial support.

Headteachers were asked to state whether there were other mechanisms applied to source for funds apart from those listed in the questionnaires. Two (13\%) of 15 head teachers reported that at times they managed to get some money from the FPE kitty which is not allowed by the government as FPE does not cater for the preschool unit. Furthermore FPE money is barely adequate to cater for the needs of primary school pupils. A study by WERK (2004) on the participation of OVC in FPE in Kenya revealed that under FPE all pupils are allocated Ksh 1,020 and an additional flat rate of Ksh2000 for the children with Special Needs. This amount was not adequate as pupils who are orphans and poor required feeding, special facilities and clothing. The study suggested that there is need to allocate money according to specific needs of pupils in a school especially those with Special Needs. Out of this it can be concluded that though some head teachers were able to secure from FPE to support OVC in nursery schools this support system could not be relied upon as a permanent solution to ensuring retention of OVC in schools.

\section{Conclusions and Recommendations}

The findings of this study indicate that the sources of funding and the mechanisms through which revenue is raised at the
ECE level have implications on adequacy and sustainability of school programmes for mainstreaming support systems for OVC in PNS in Nyeri Central district. As the study found out school fees paid by parents was seen to provide the needed source of revenue yet the burden seemed too much especially when children, OVC included had to be sent home often to collect school fees. Headteachers could not afford to purchase files for individual child progress and awareness of OVC lacked concrete data as MOE depended on verbal reports given by the teachers. The financial support for OVC was hidden in other programmed school vote heads such as teacher remuneration, which were more prioritized in the schools before the needs for OVC were met. This has made support for OVC in the schools erratic and thus mainstreaming support for OVC has been compromised as parents and well wishers were identified as largest proportion of funding systems. Though the highest percentage of the received funds was allocated to teacher salaries the pay was very low for majority of the teachers (less thanKsh5,000)

Inadequacy of funds had ripple effects on establishment and sustainability of support structures for OVC. Headteachers allocated less funds to school feeding programme while others did not have the programme. This posed challenges to OVC retention as feeding programmes is an important support structure for children from poor homes. Owing to lack of specific funding systems for OVC majority faced problems associated to lack of school fees as well as lack of school uniform and learning materials. Though majority of the schools mitigated the problems by appealing to the well wishers while a few others mobilized the community for funds, requiring parents to raise all the school revenue resulted in high degree of inequality in per pupil funding. From this study it is evident that though funds were available from the parents and some well wishers they could not be relied on as they were inadequate to cater for ample allocation to OVC support systems in PNS.

Based on the conclusions discussed in the previous section the study makes the following recommendations:

i. PNS management should seek for alternative sources of funding to facilitate their operations as well as 
mainstreaming support for OVCs. The fact that school fees from parents constitute the main source of finance in ECE centers is critical considering the high poverty levels in the district. This would reduce their reliance on parents and well wishers as the chief sources of finance.

ii. Stakeholders of public nursery schools should improve the remuneration of teachers. Apart from paying the salaries and allowances to teachers from the funds received by the school, the schools may approach institutions such as government and non governmental agencies to pay the teachers. Such organizations and agencies include Teachers Service Commission (TSC), Faith Based Organizations (FBO) among others. This will reduce spending all the available funds on teachers' salaries as well as improving their working conditions.

iii. Allocation of funding among the competing needs should be made more prudent. This involves targeting the needs that are most deserving and establishing right priorities. For instance more funding should be allocated towards feeding programme and acquisition of teaching and learning materials. Capacity building should target all the teachers as they are critical to the development of integrated and sustainable services to the children. Training programmes for ECE teachers should continue on the job and follow up should continue even after formal training in order to promote awareness and needs assessment which is vital to the mainstreaming of support for OVC.

\section{References}

[1] Abebe, T.(2009). Orphan hood, Poverty \& The Care Dilema: Review of Social Trends. A journal of Social Work\&Society. Vol 7 (1) 70-84

[2] Bartlett, J. Kortlik J. and Higgins, C.(2001).Determining Appropriate Sample Size For Survey Research. A Journal Of Information Technology Learning And Performance. Vol 19 (1)

[3] Belfield, R.(2006). Financing Early Childhood Care And Education; An International Review. Queens College. Newyork

[4] Boler, T. and Carroll, K. (2003). Addressing the educational Needs of Orphans and Vulnerable Children. Policy and Research issue No 2.

[5] Government of Kenya (2001). Children's Act. Government printer. Kenya

[6] Government of Kenya.(2005). National Policy on Orphans and Vulnerable Children, Nairobi, Government printer.

[7] Government of Kenya (2003).National Action Plan on Education For All 2003-2015.Govrnment printer

[8] Government of Kenya. (2005). Ministry of Education strategic plan 2006-2011.Nairobi

[9] Kidner C. and Curtis, S (2003). Mainstreaming Equality Issues. Spice briefings $03 / 58$ page 3 .
[10] Krejcie R. and Morgan, W. (1970). Educational and Psychological Measurement: Determining Sample Size for Research Activities. (30) 607-610.

[11] Lusk, D. Huffman, and O'Gara, C.(2000). Assessment and Improvement of Care of aids Affected Children under Age 5.Agency for Educational Development. Washington DC.

[12] MGCSD. (2007).National Action Plan for Orphans and Vulnerable Children in Kenya 2007-2010. Nairobi. Government Printer.

[13] Mishra V., Anorld F., Otieno F. Cross, A. and Hong, R (2005).Nutritional Status of Orphans and Children of HIV infected parents of Kenya. Vol no24.

[14] MOGCSD. (2011). Cash Transfer Funds For Orphans And Vulnerable Children. Nairobi. Government Printer.

[15] Mugenda, O. and Mugenda, A.G. (2003). A Research Methods: Quantitative and Qualitative Approaches, Nairobi, Acts press.

[16] Paul,L. Ann, P. and Cruickshank, M. (1977). Mainstreaming. A Practical Guide. Syracuse University Press.

[17] Pfeiderer, R .and Kantai, O. (2010). Orphans and Vulnerable Children (OVC) Programming in Global Fund HIV Grants in Kenya. Washington DC

[18] Smart, R. (2003). Policies for Orphans and Vulnerable Children. A Framework For Moving Ahead Availableasat $3^{\text {rd }}$ jan2011.http//www.hivaidsclearinghouse.unes co.org/search/resources/ovc - policies -pdf

[19] Subbarao, K. and Coury, D. (2004). .Reaching Out To Africa's Orphans. A Framework For Public Action. Washington DC. World Bank

[20] UNESCO, (2005).Early Childhood Care and Family Series: Early Childhood and Education in Kenya. No 11-2005 Paris. France.

[21] UNESCO, (2008). EFA Goal Monitoring Report; Overcoming Inequality: Why Governance Matters. France

[22] UNICEF. (2009). Promoting Quality Education for Orphans and Vulnerable Children. A Source Book of Programme Experiences in Eastern and Southern Africa.

[23] UNICEF. (2004). Children on the Brink 2004: A Joint Report of New Estimates and A Framework For Action. New York. United Nations Children Fund

[24] UNICEF(2009).Child Friendly Schools. http://www.unicef.org/devprov/files/CFS manual-ch06-05 2009.

[25] USAID. 2008. Education Programming for OVC affected or Vulnerable to HIV. Moving beyond School fees and uniform. Washington DC

[26] USAID. (2010).Orphans and Vulnerable Children (OVC) Programming in Global Fund HIV Grants in Kenya. Washington DC.

[27] USAID. (2009). Kenya Research Situation Analysis On Orphans And Vulnerable Children; A Country Brief. Boston University and University of Nairobi. 